\title{
Suppression of the acquisition footprint for seismic sequence attribute mapping
}

\author{
Kurt J. Marfurt*, Ronald M. Scheet ${ }^{\ddagger}$, John A. Sharp ${ }^{\ddagger}$, \\ and Mark G. Harper**
}

\begin{abstract}
Seismic coherency has proven to be very effective in delineating geologic faults as well as considerably more subtle stratigraphic features, including channels, canyons, slumps, levees, glacial gouges, dewatering patterns, and pinnacle reefs. Unfortunately, seismic coherency estimates, which quantitatively measure the similarity or dissimilarity of adjacent traces in 3-D, are particularly sensitive to coherent noise that passes through the acquisition and processing flow. They are also sensitive to dissimilarities in fold, offset, and azimuth distribution introduced through the 3-D acquisition and binning processes. Edge enhancement algorithms further exacerbate these linear artifacts.

We define the acquisition footprint to be any pattern of noise that is highly correlated to the geometric distribution of sources and receivers on the earth's surface. While the strong acquisition footprints such as those caused by normal moveout (NMO) stretch on vintage single-fold data have been largely ameliorated by modern 2-D multifold recording, we see acquisition 3-D footprint in the
\end{abstract}

low-fold shallow section and throughout the entire section when recording sparse 3-D land surveys that often result in only six- to sevenfold data.

One may partially suppress the acquisition footprint on the seismic coherency time or depth slices using conventional 2-D image processing. Unfortunately, such filtering is inappropriate for dip/azimuth maps, cluster analysis maps, and other maps that may not be continuous real variables or with maps that have cyclic values, such as the wavelet phase. We show that simple 3-D true-amplitude dip filtering of the input 3-D $(t, x, y)$ time- or depth-migrated seismic data volume can be quite effective in minimizing the detrimental effect of the acquisition footprint on conventional 3-D seismic attributes for both marine and land data acquisition geometries. However, 3-D dip filtering of migrated data will often eliminate the fault-plane reflections necessary for sharp coherency images. We therefore recommend that, whenever possible, suppression of acquisition footprint be performed before 3-D migration on the stacked data volume, where sharp fault truncations in depth are represented by smoothly varying diffractions in time.

\section{INTRODUCTION}

Seismic coherency, as originally developed by Bahorich and Farmer $(1995,1996)$ in the C1 algorithm, involves a calculation of apparent dip in the in-line and cross-line directions of the seismic survey. The phase lag or advance having the greatest (most positive) crosscorrelation coefficient is declared to be an estimate of the apparent dip, with the crosscorrelation coefficient itself being a measure of $2-\mathrm{D}$ coherency. The $3-\mathrm{D}$ coherency is then estimated by taking the geometric mean of the 2-D coherencies calculated in the two orthogonal directions. In principle, there should not be any change in coherency across a knife-edge fault that simply displaces a suite of coherent seismic reflectors having identical waveforms. On the other hand, the coherency algorithms that use three or more traces in any given direction are quite sensitive to vertical displacement of a coherent reflector along a fault. These algorithms include the $\mathrm{C} 2$, or semblance-based coherency algorithm (Marfurt et al., 1995), and the C3, or eigenstructure-based coherency algorithm (Gerstzenkorn and Marfurt, 1996), which provide more robust estimates of coherency over an arbitrary analysis window of traces. In practice, any of the following fault-related events may give rise to low seismic coherency (Figure 1):

Presented at the 65th Annual International Meeting, Society of Exploration Geophysicists. Manuscript received by the Editor December 6, 1996; revised manuscript received September 22, 1997.

*Amoco EPTG, Geoscience Technology, P.O. Box 3385, Tulsa, OK 74102-3385. E-mail address: kmarfurt@amoco.com.

$\ddagger$ Amoco WEBG, Trinidad Exploration Team, 501 West Lake Park Blvd., Houston, TX 77079-2696. E-mail: rmscheet@amoco.com; jasharp@ amoco.com

**AEGNA, Amoco Canada Production Gas BU, 240 Fourth Ave. SW, Calgary, Alberta, Canada. E-mail: mgharper@amoco.com.

(C) 1998 Society of Exploration Geophysicists. All rights reserved. 
1) differential compaction,

2) erosion of an upthrown block,

3) greater formation thicknesses in a downthrown growth fault block,

4) differences in lithology caused by sediment transport along the fault in syndepositional settings,

5) differential velocities in depth-migrated data such as those caused by pore pressure compartments,

6) diagenetic effects along the fault itself, and

7) finite thickness shattered fault zones versus a highly localized fault plane or surface.

Unfortunately, there are additional changes in reflector wavelet shape that are not attributed to geology but rather are due to compromises made in seismic acquisition and processing. Figures 2 and 3 show a 2-D vertical section and a horizontal time slice extracted from a 3-D time-migrated survey from offshore Trinidad. While the north-south striations are

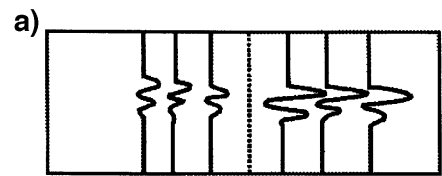

c)

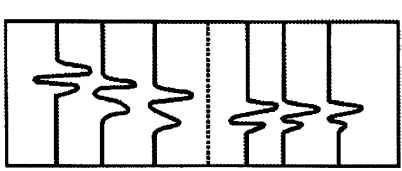

e)

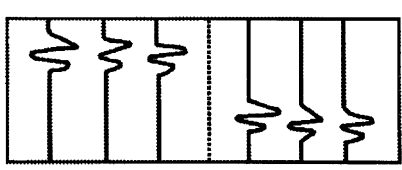

clearly visible on the time slice in Figure 3, it would not greatly hamper its interpretation. In addition to amplitude balancing, there appears to be some leakage of low-velocity noise as well as some overmigration. These striations appear as subtle traceto-trace variations in amplitude and waveform in the west-east vertical section corresponding to line $\mathrm{AA}^{\prime}$ (Figure 2).

We use the term acquisition footprint to describe that component of the seismic data which mirrors some part of the acquisition geometry. Although there is no single cause of acquisition footprint, coherent, aliased, backscattered noise is always present to some degree (Regone and Rethford, 1990). While in-line receiver and cross-line shot arrays are used commonly in both marine and land environments, the principle of surface consistent acquisition discussed by Vermeer (1990) suggests that 3-D arrays should be used on both sources and receivers to properly suppress steep-dip, high-energy, side-scattered noise. Other sources of acquisition footprint include

b)

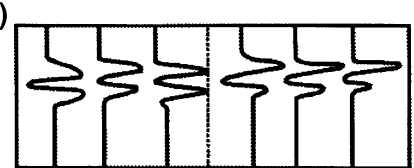

d)

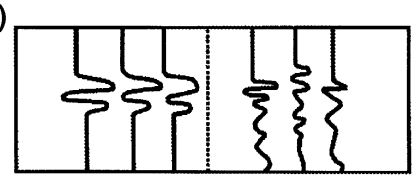

FIG. 1. Factors affecting seismic coherency across a vertical fault (dotted line): (a) change in amplitude, (b) change in phase, (c) change in dip and/or dip azimuth, (d) change in reflector coherency, and (e) change in fault intercept time (fault displacement).

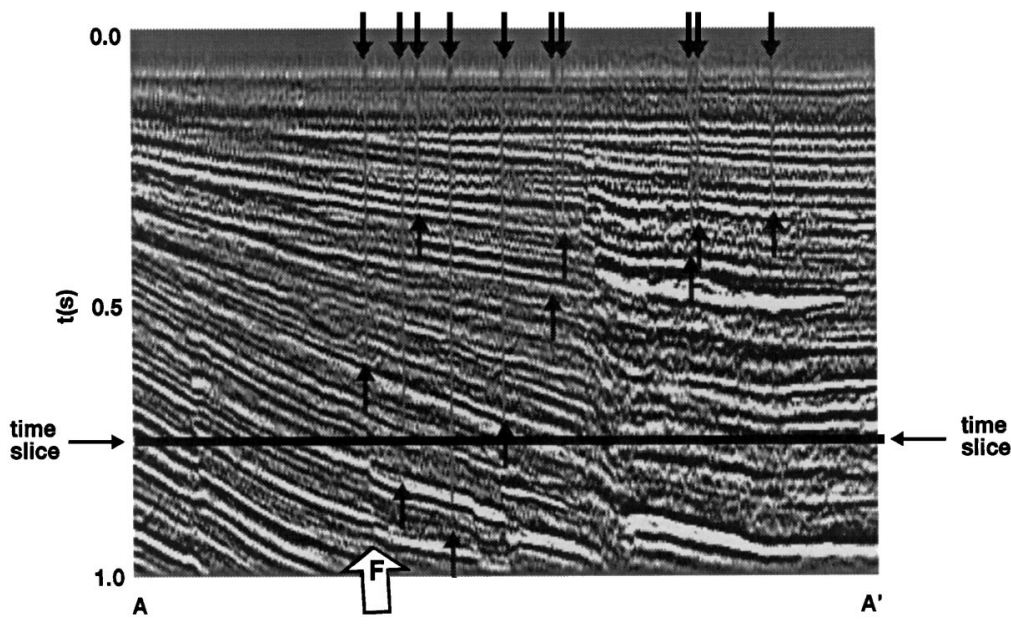

FIG. 2. An example from offshore Trinidad. A vertical slice taken perpendicular to the acquisition footprint corresponding to line $\mathrm{AA}^{\prime}$ in Figure 3 . Black arrows denoted partially filled bins. Fault $\mathrm{F}$ corresponds to the fault labeled $\mathrm{FF}^{\prime}$ in Figure 4. 


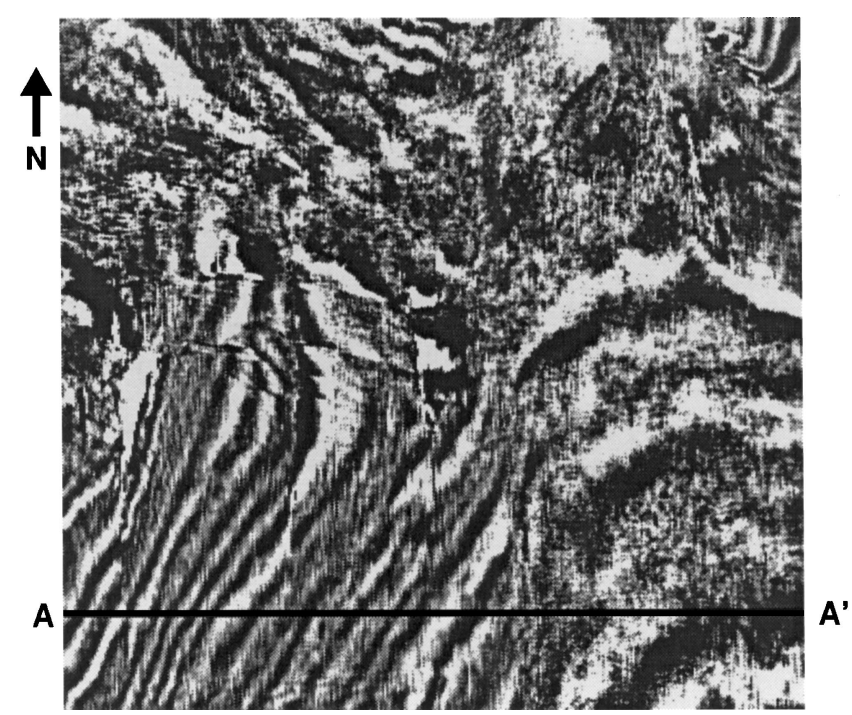

FIG. 3. Time slice at $750 \mathrm{~ms}$ through a 3-D time-migrated seismic data cube from offshore Trinidad.

a)

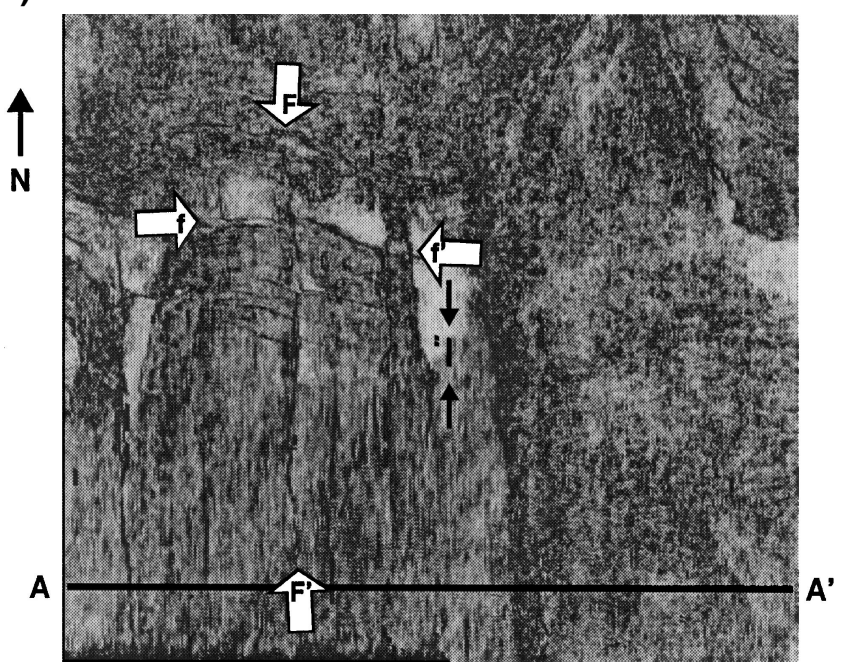

c)

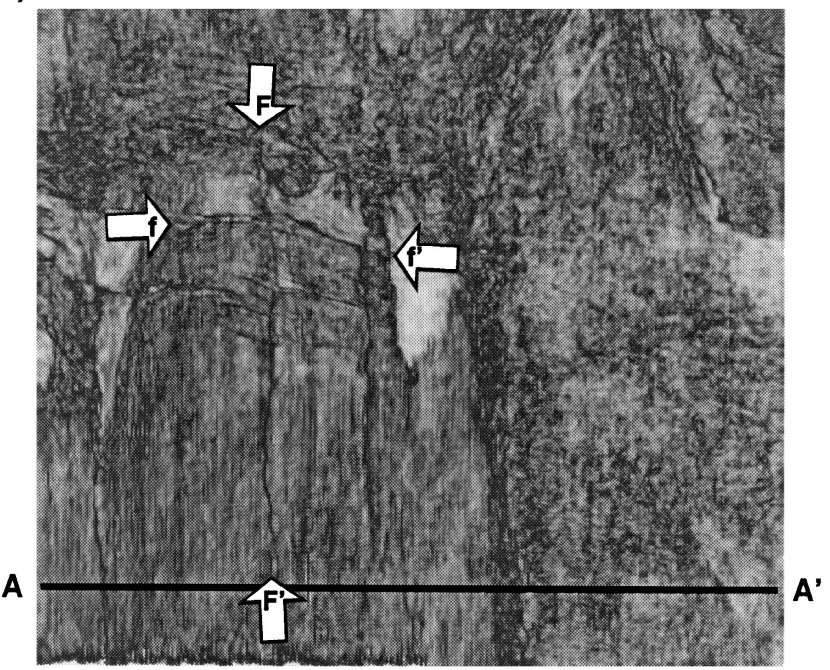

1) acquisition design choices that bias the data binning in terms of offset and azimuth, resulting in biased NMO stretch and amplitude variation with offset (AVO) effects on the reflection signal,

2) uncontrollable systematic effects on the acquisition equipment, such as cable feathering due to strong currents, and

3) processing errors such as introduced by $2-\mathrm{D}$ migration, over- and undermigration, or nonisotropic handling of coherent aliased noise by coarse-grid 3-D dip moveout and migration algorithms.

Unfortunately, these artifacts are highly exacerbated by the $\mathrm{C} 1$ coherency algorithm (Figure 4a). More robust algorithms such as the $\mathrm{C} 2$ coherency algorithm using an 11-trace analysis window and the $\mathrm{C} 3$ algorithms using nine traces are also sensitive to these artifacts (Figures $4 b$ and $4 c$ ).

The simplest way to suppress this specific acquisition footprint is through 2-D image processing of the coherency time slices. The $\left(k_{x}, k_{y}\right)$ filtered coherency time slice shown in Figures $4 \mathrm{a}-\mathrm{c}$ is displayed in Figures $5 \mathrm{a}-\mathrm{c}$. Unfortunately, while we

b)

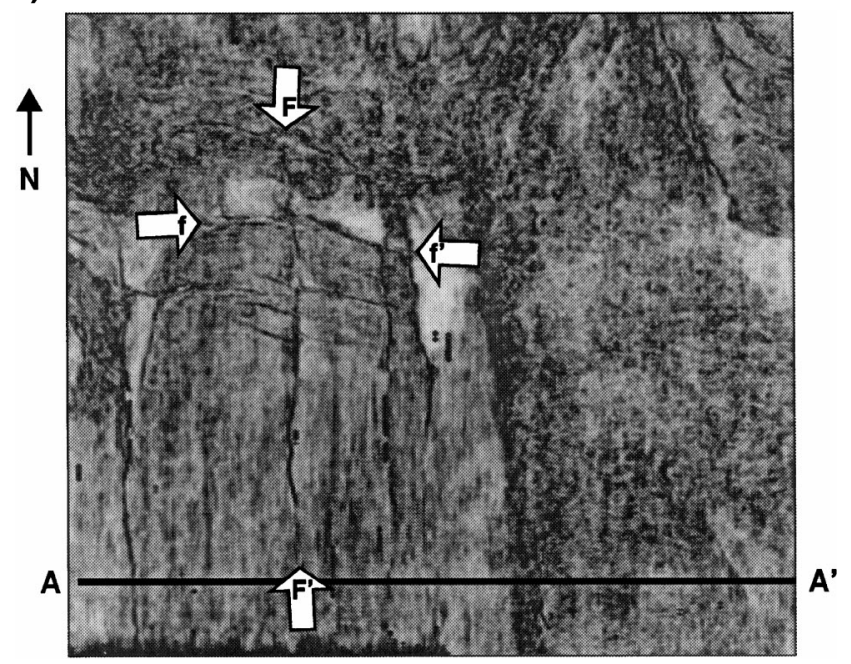

FIG. 4. Time slice at $750 \mathrm{~ms}$ through the coherency cube generated from the data in Figure 3 using the (a) C1, (b) C2, and (c) $\mathrm{C} 3$ algorithms. Black arrows denote empty bins. 
have suppressed a great many linear artifacts, we have also excised the north-south faults such as $\mathrm{FF}^{\prime}$ dominant in this geologic terrane. Furthermore, other attributes are also sensitive to the acquisition footprint. Wavelet phase (Bodine, 1984) appears to be the most sensitive of the conventional attributes (Taner et al., 1979), showing up as strong colored streaks on the time slice (Figure 6). Any simple time slice filtering technique would destroy information wherever the phase, $\psi$, wraps from $+180^{\circ}$ to $-180^{\circ}$. While one could filter the continuous variables, $\cos \psi$ and $\sin \psi$, this results in a nonlinear filter over different parts of the phase cycle. Other attributes such as the color index used to display dip/azimuth or the population number used in classification, clustering, and discriminant analysis maps are often stored as discrete integers and not as floating point numbers. Such integer maps are not amenable to spectral filtering.

Finally, for large data sets, time slice filtering the results of seismic attribute calculations results in two or more interme-

a)

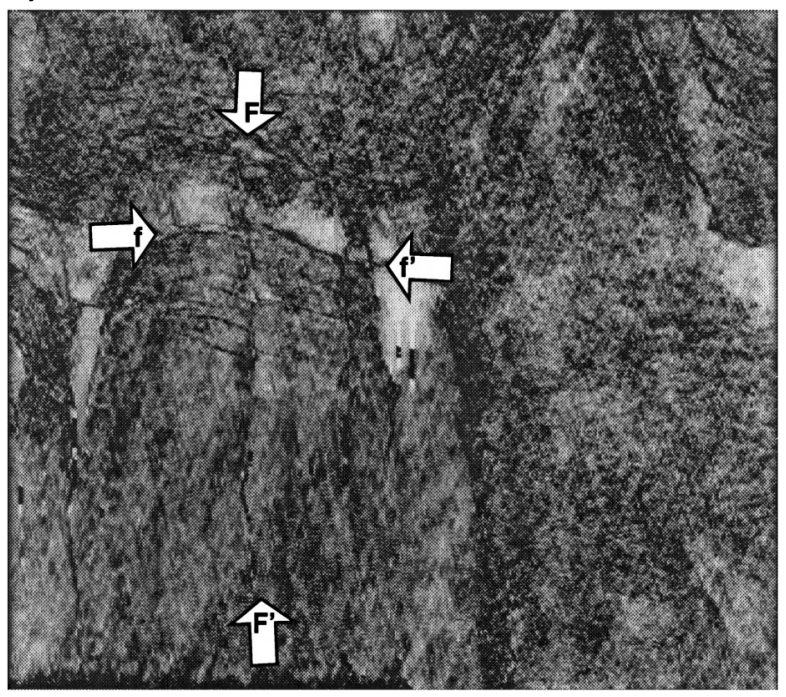

c)

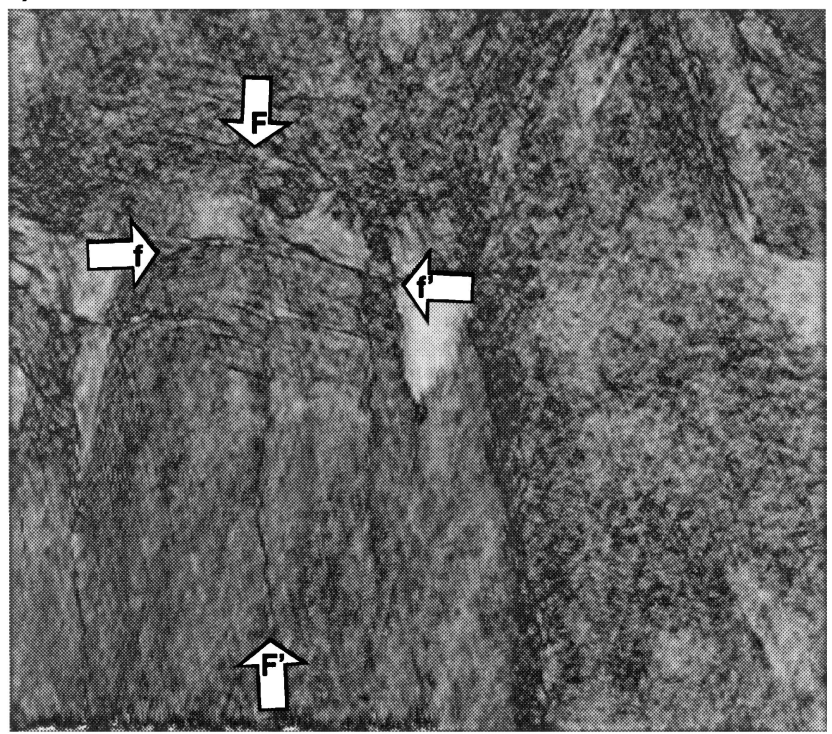

diate data volumes for each attribute because the attribute cube must be rotated from $(t, x, y)$ ordering to $(x, y, t)$ ordering, after which the filtered attribute cube must be rotated back for $(x, y, t)$ ordering to $(t, x, y)$ ordering. Such extra attribute cubes (sometimes exceeding 100 Gbytes in size) quickly consume the disk resources of all but the largest interpretive workstations. We therefore find it more expedient to filter the original seismic data cube corresponding to Figures 2 and 3 prior to the calculation of coherency and other seismic attributes.

\section{SUPPRESSION OF ACQUISITION FOOTPRINT ON MARINE DATA}

The exploration plays in Trinidad are primarily structural, requiring the detailed mapping and dating of a great many fault blocks. The waters off Trinidad are plagued by strong currents giving rise to significant cable feathering, which varies with both

b)

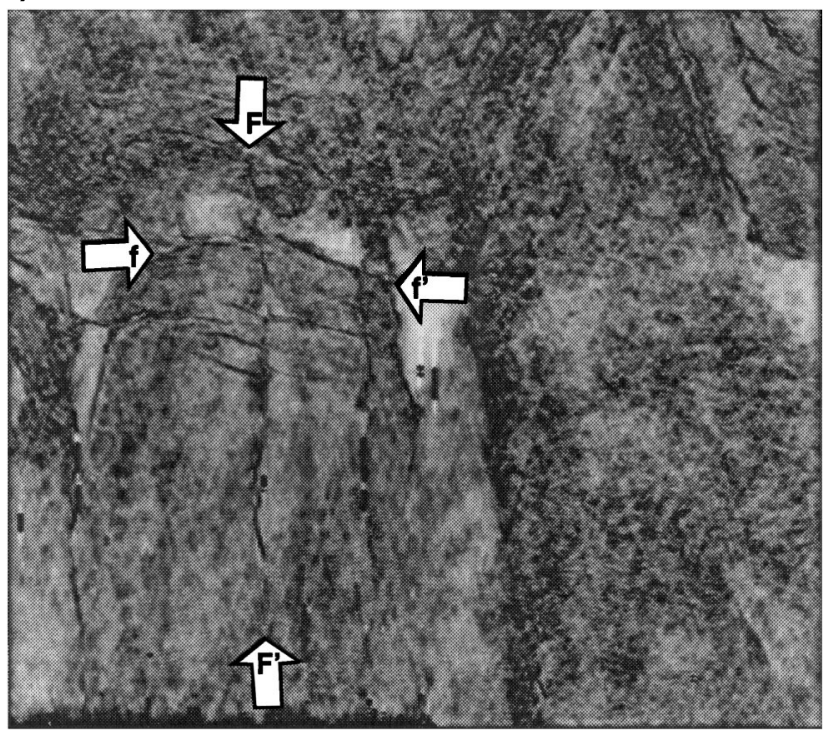

FIG. 5. Filtered coherency obtained by 2-D Fourier $\left(t, k_{x}, k_{y}\right)$ time slice filtering of the data shown in Figure 4 for the (a) $\mathrm{C} 1$, (b) $\mathrm{C} 2$, and (c) $\mathrm{C} 3$ algorithms. 
Marfurt et al.

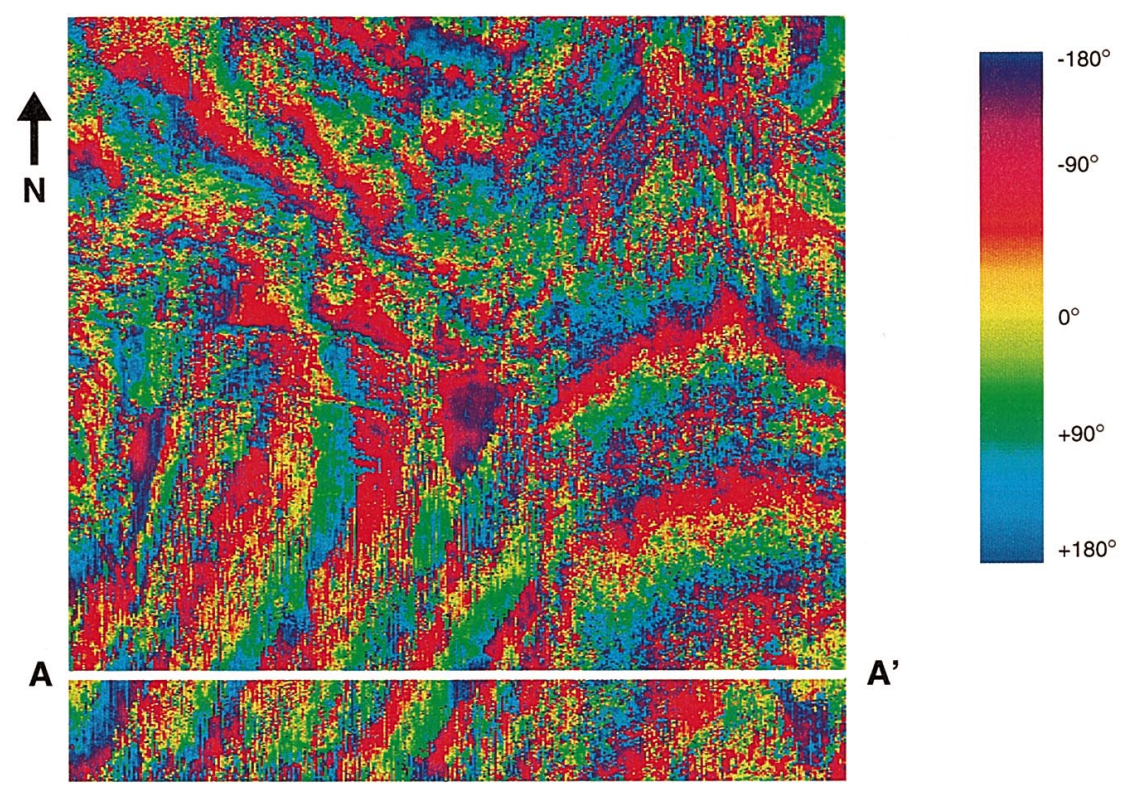

FIG. 6. Response phase time slices corresponding to unfiltered data and time level shown in Figure 3.
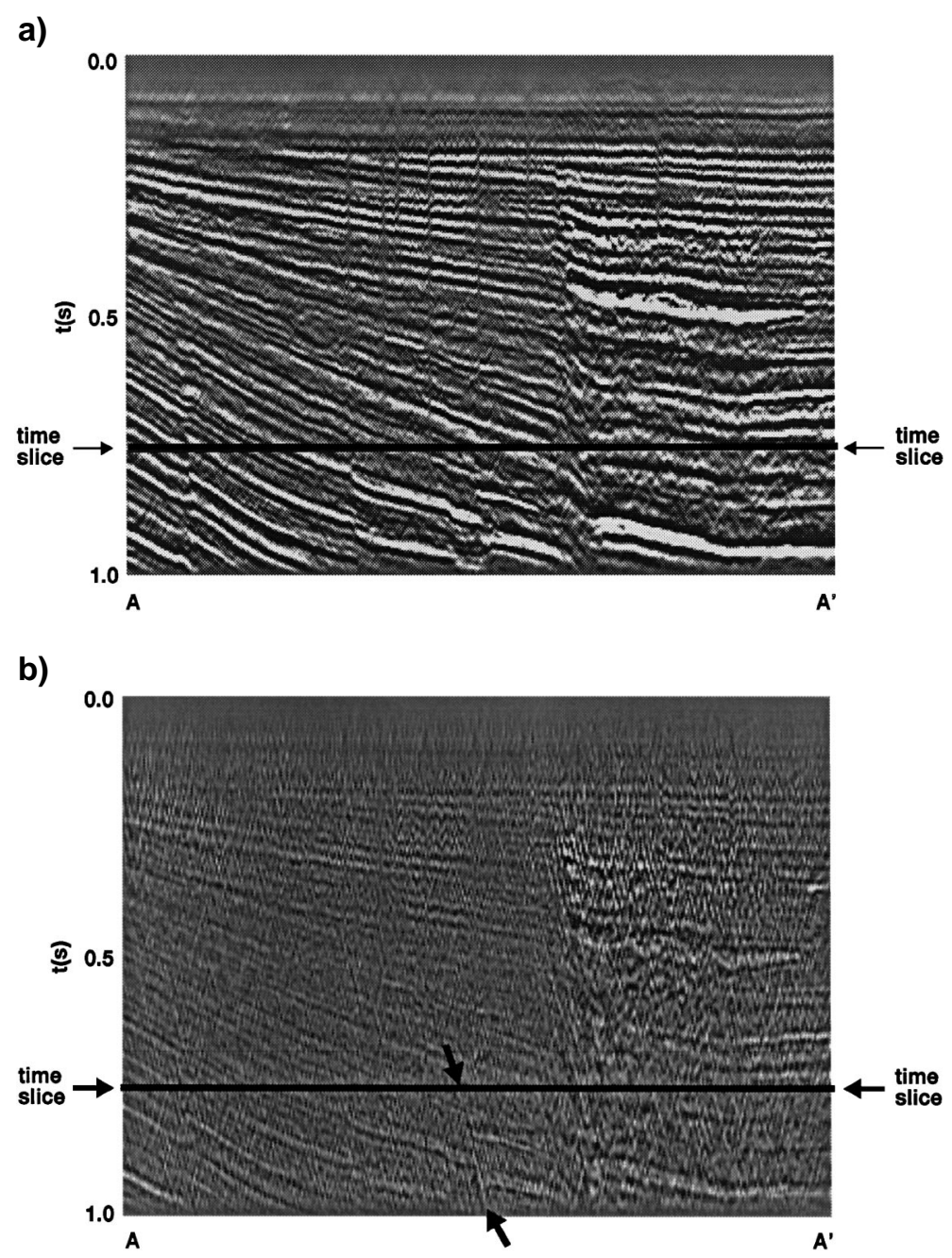

FIG. 7. (a) Filtered seismic data along $\mathrm{AA}^{\prime}$ after 3-D dip filtering. (b) Rejected noise obtained by subtracting Figure 7 a from Figure 2. Note undesired rejection of aliased signal along with noise. Arrows indicate a fault-plane reflection that fell within the dip reject band. 
a)

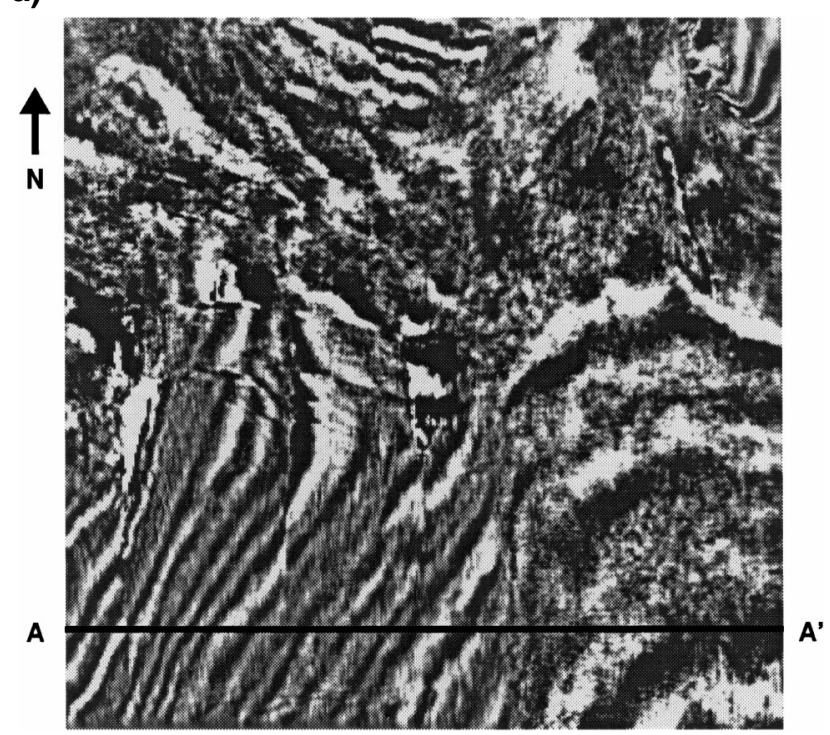

b)

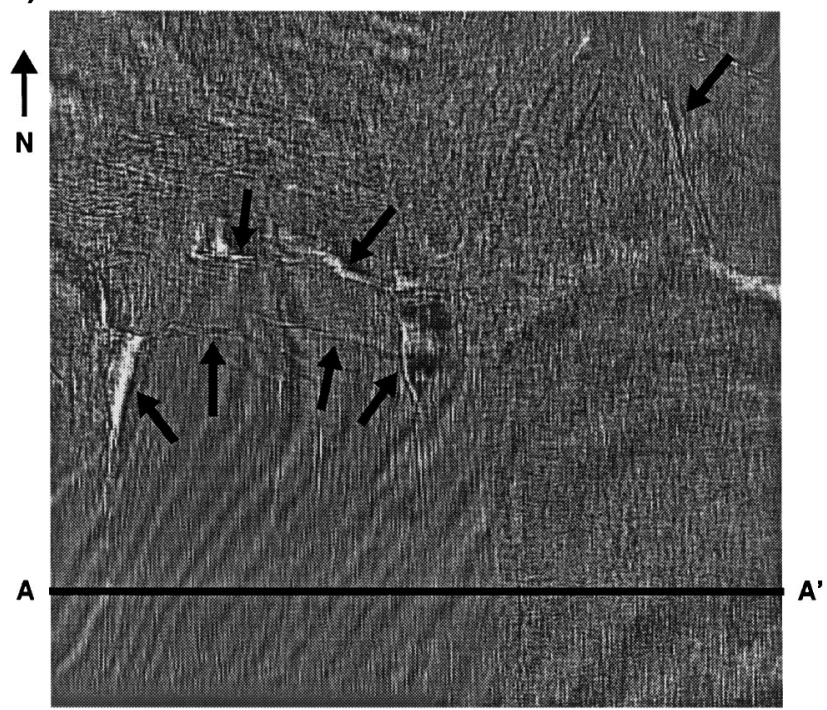

FIG. 8. (a) Time slice of filtered seismic data at $750 \mathrm{~ms}$ after 3-D dip filtering. (b) Rejected noise obtained by subtracting Figure 8 a from Figure 3 . Note undesired rejection of aliased signal along with noise. Arrows indicate fault-plane reflections that fell within the dip reject band.

a)

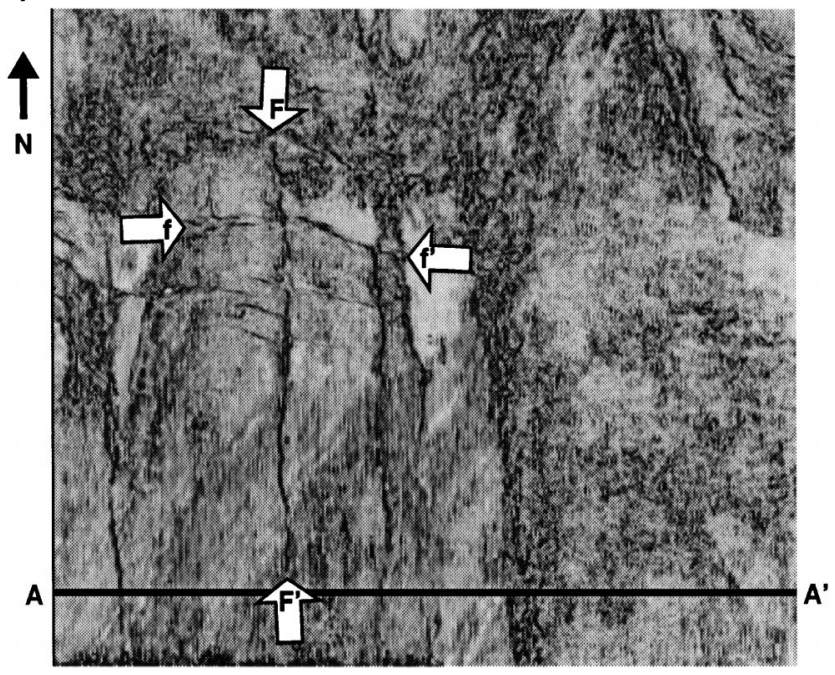

c)

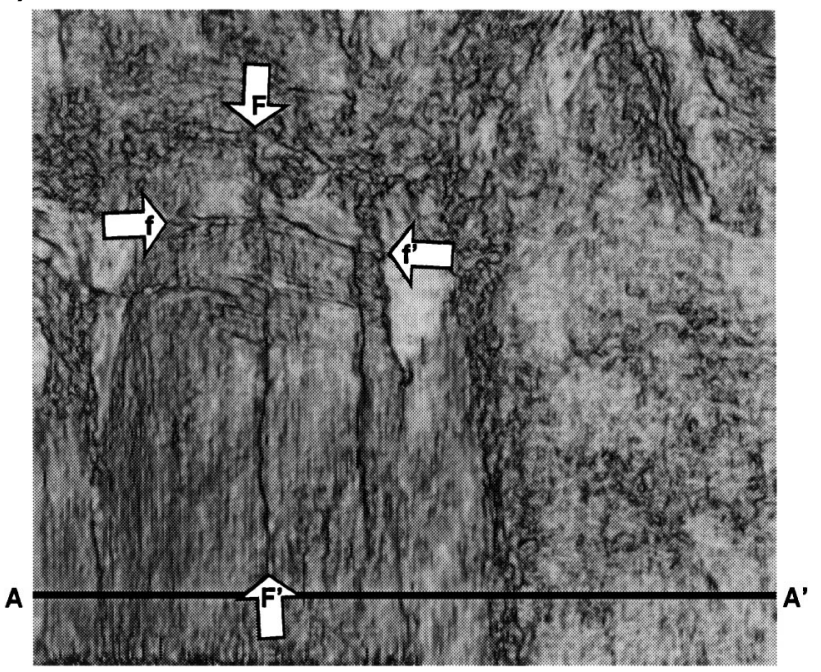

b)

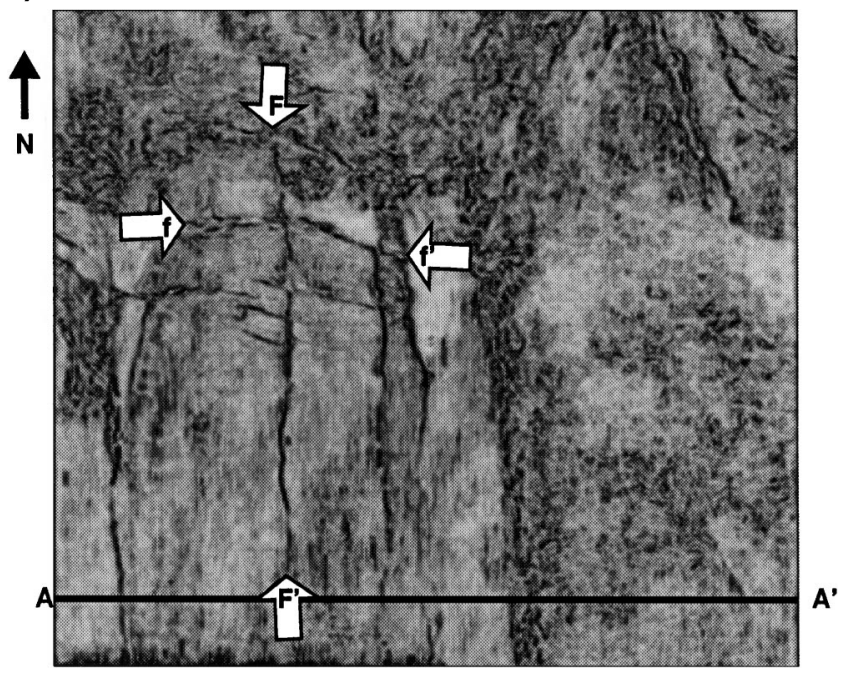

FIG. 9. Time slice at $750 \mathrm{~ms}$ through coherency cube run on filtered data corresponding to Figure 8 a for the (a) $\mathrm{C} 1$, (b) $\mathrm{C} 2$, and (c) C3 algorithms. 


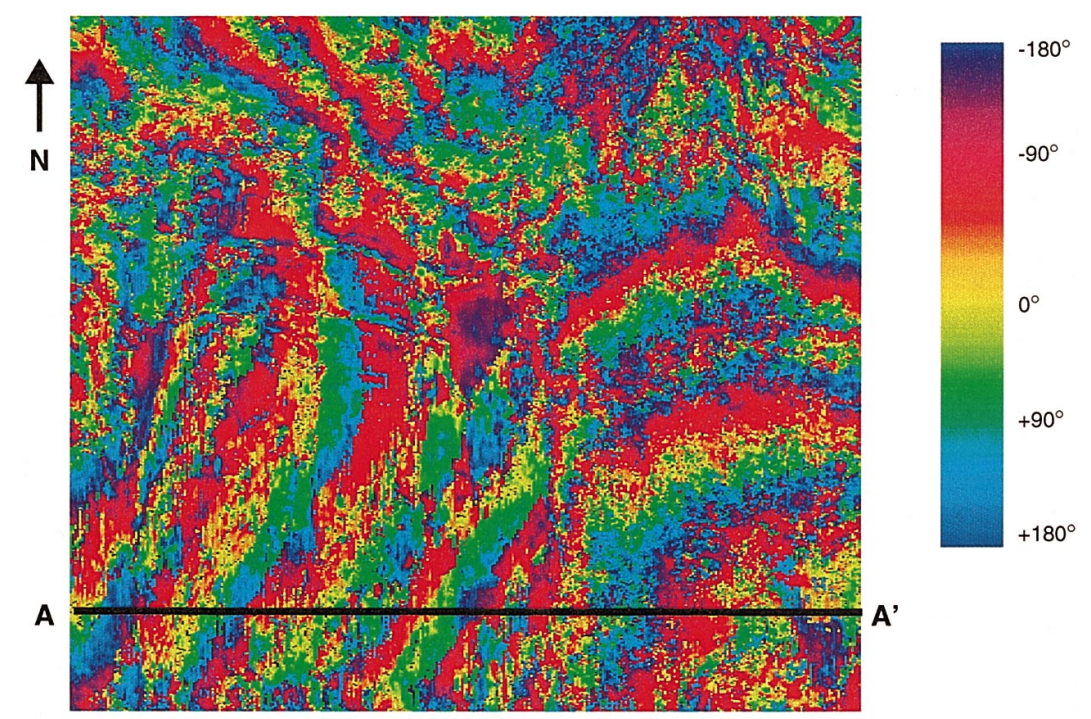

(a)

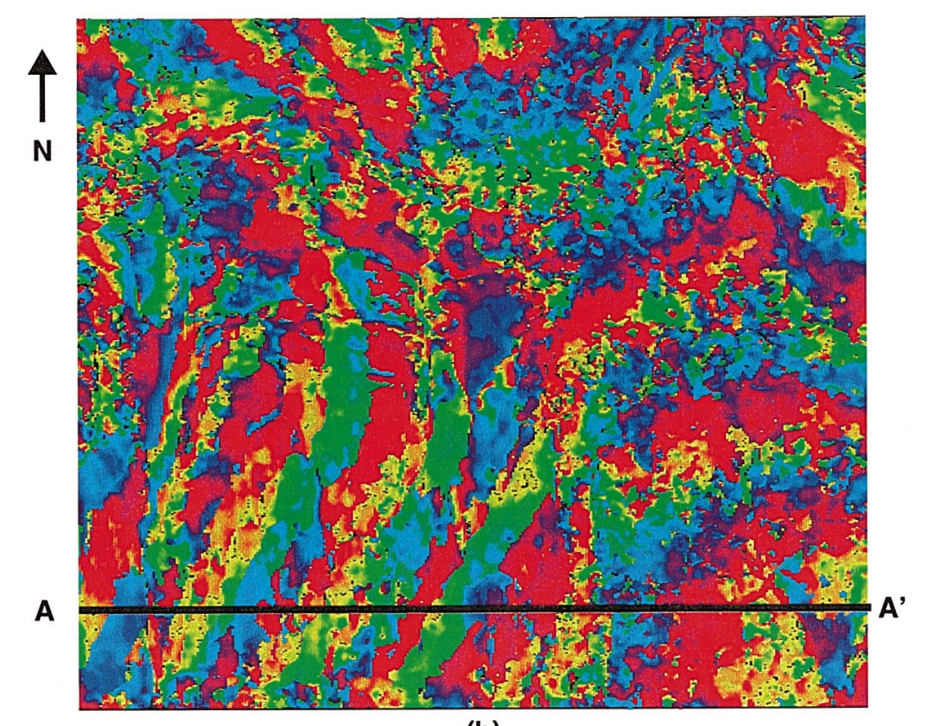

(b)

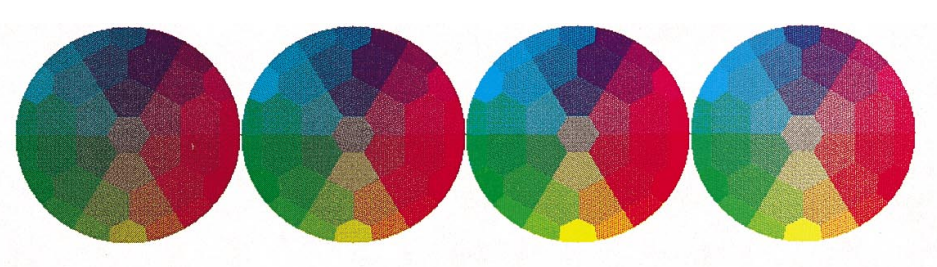

FIG. 10. Time slice at $750 \mathrm{~ms}$ through (a) the wavelet phase cube generated from the filtered seismic data corresponding to Figure $8 \mathrm{a}$ and (b) the reflector wavelet slice shown in Figure 11. Compare to wavelet phase of unfiltered data in Figure 5.

A

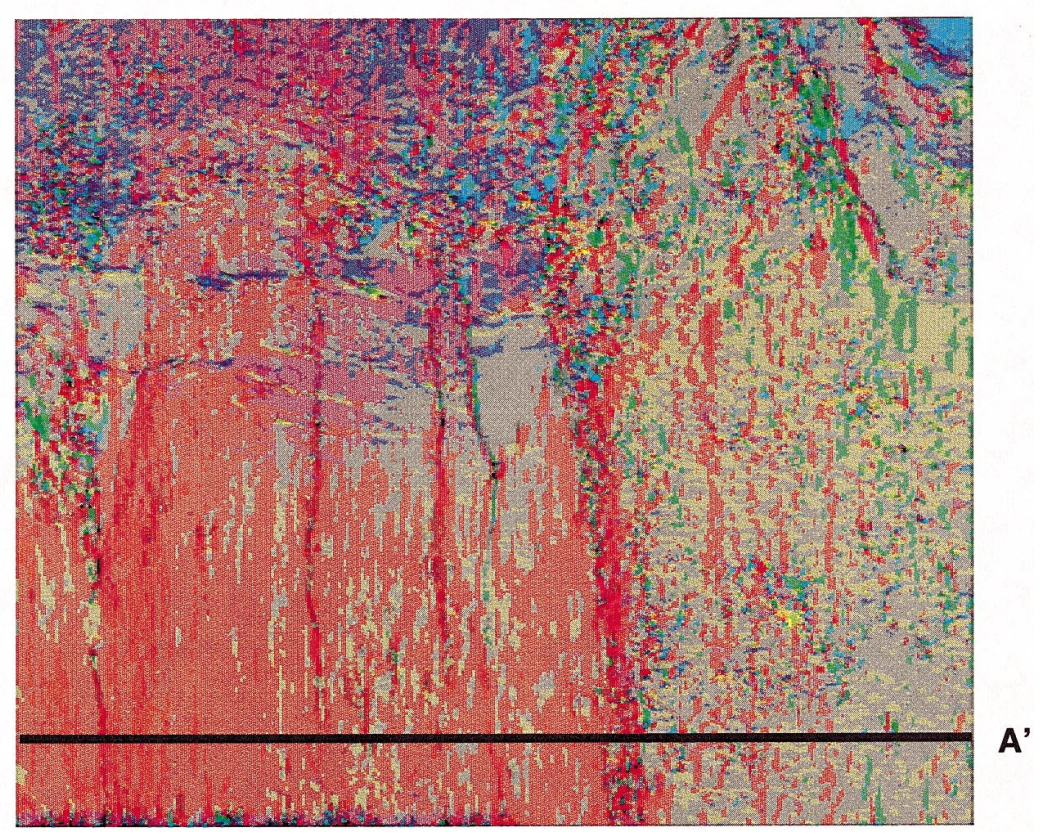

FIG. 11. Time slice at $750 \mathrm{~ms}$ through dip/azimuth cube corresponding to $\mathrm{C} 2$ coherency calculation of Figure $9 b$. 
weather and tides. Picking up a survey after a brief hiatus may result in jumps of this cable feathering, giving rise to low-fold bins in the data (Figure 2). While the major faults are clearly visible on the seismic data (Figures 2 and 3), the seismic coherency cube gives us a very quick look at the structural fabric at all scales-from major $\mathrm{N}-\mathrm{S}$-trending faults ( $\mathrm{FF}^{\prime}$ in Figure $4 \mathrm{~b}$ ) to shorter E-W-trending cross faults (ff' in Figure 4b). The associated subtle fault blocks can be of significant interest once the production platform is already in place.

The simplest 3-D dip filter would be to transform the entire data volume into the $\left(\omega, k_{x}, k_{y}\right)$ domain, where one would apply an appropriate mute and transform back to the $(t, x, y)$ domain. While 3-D Fourier transforms of 100-Gbyte data volumes are readily performed by large-memory, high-performance computers, they are beyond the capabilities of most present-day interpretive workstations. Indeed, only recently have the most popular interpretive workstations been able to read and write single files exceeding 2 Gbytes in size. We therefore turn our attention to the design of smaller running window 3-D dip filters. Although one could design a small running window $\left(\omega, k_{x}, k_{y}\right)$ dip filter, we choose to filter in the $(\tau, p, q)$ domain using an efficient running window discrete Radon transform. For poorquality data, the $(\tau, p, q)$ approach provides the possibility of poststack $(\tau, p, q)$ predictive deconvolution as well as nonlinear weighting of the coherent signal. For the two data sets in this paper, we will simply exploit the dip-filter capabilities of the $(\tau, p, q)$ transform. Indeed, since we are primarily interested

a)

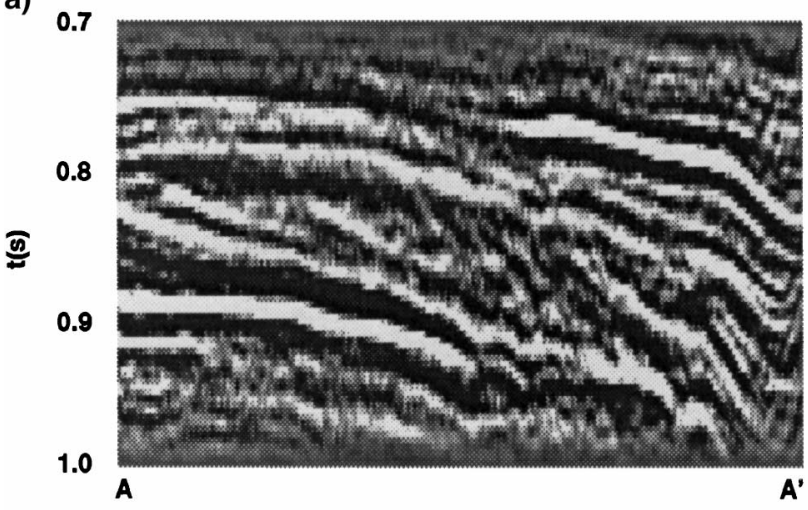

c)

0.7

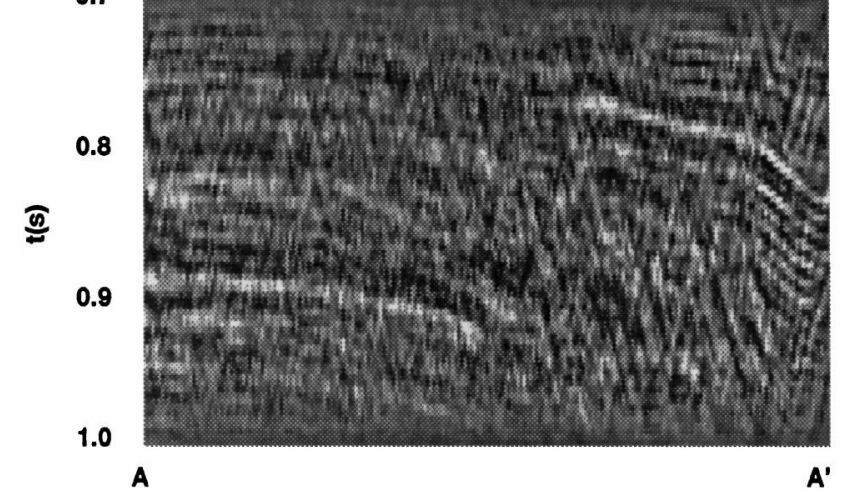

in suppressing the nearly rectilinear acquisition footprint, a much more economical 2-D $(\tau, p)$ by 2-D $(\tau, q)$ filter is sufficient. Both discrete Fourier $\left(\omega, k_{x}, k_{y}\right)$ and discrete Radon $(\tau, p, q)$ transforms allow us to filter noise events beyond the spatial Nyquist criterion of the orthogonal fast Fourier transform. However, in the absence of additional a priori information (Marfurt et al., 1996), some component of the desired signal will inadvertently leak, or alias, into the noise reject band. Therefore, considerable care needs to be taken in assessing which frequency components of the signal have been damaged in our attempt to suppress aliased noise. Figure 7 shows the filtered data and rejected "noise" after application of a $(\tau, p, q)$ discrete Radon transform filter that least-square modeled the apparent dips, $p$ and $q$, for $|p|$ and $|q|<0.75 \mathrm{~s} / \mathrm{km}$ using a 441-trace operator. Defining the true dip $s^{2}=p^{2}+q^{2}$, we rejected dips with $0.6 \mathrm{~s} / \mathrm{km}<|s|<0.75 \mathrm{~s} / \mathrm{km}$, passed dips $|s|<$ $0.4 \mathrm{~s} / \mathrm{km}$, and tapered the amplitude of dips $0.4 \mathrm{~s} / \mathrm{km}<|s|<$ $0.6 \mathrm{~s} / \mathrm{km}$.

Clearly, such dip filtering poses the risks of removing any steep fault-plane reflections. Such detrimental effects are most easily circumvented by attacking the acquisition footprint prior to 3-D time or depth migration, where the acquisition footprint has apparent "dips" that are unphysically slow and where sharp fault edges are still in the form of smooth diffractions. Since the time migrated data are readily available on the interpretation workstation, we compromise and note that since our immediate objective is to analyze coherency only for the true dip, $d$, where

b)

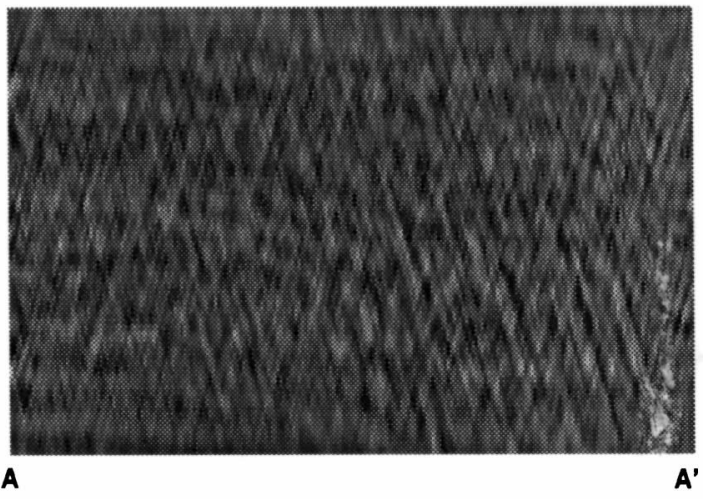

d)

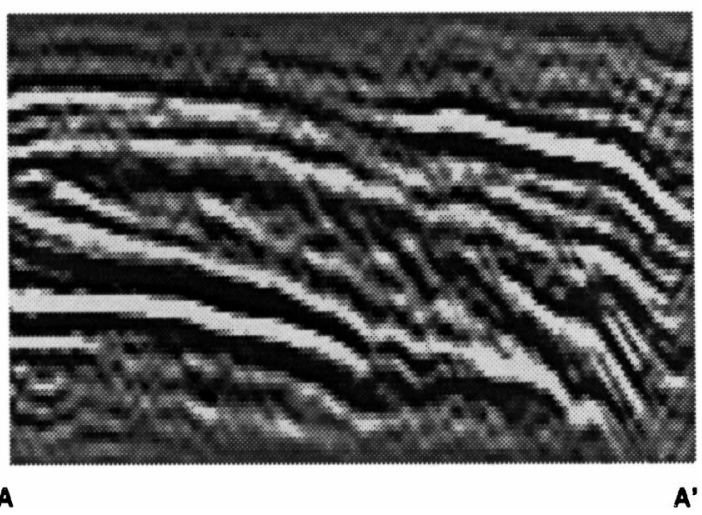

FIG. 12. An example from the Permian basin, Texas. A vertical slice taken along line $A^{\prime} A^{\prime}$ of Figure 13: (a) raw data, (b) rejected noise component with dips $0.2 \mathrm{~ms} / \mathrm{m}<s<0.4 \mathrm{~ms} / \mathrm{m}$, (c) rejected noise component with dips $s>0.2 \mathrm{~ms} / \mathrm{m}$, and (d) filtered data. 
$d<0.25 \mathrm{~s} / \mathrm{km}$, corresponding to the maximum stratigraphic dip observed in the section, the elimination of possible fault-plane reflectors should not greatly affect our results. Figure 8 shows the time slice at $750 \mathrm{~ms}$ of the filtered data and rejected noise after 3-D dip filtering. As expected, we have filtered out faultplane reflections having true dips greater than $0.6 \mathrm{~s} / \mathrm{km}$. A small component of signal having shallow dip that has aliased into the reject band has also been inadvertently rejected. The major component of noise has either a north-south or east-west lineation, corresponding to binning artifacts, leakage in the stack array, or amplitude errors in the DMO algorithm.
We now calculate the seismic coherency on the filtered data cube (Figure 9). Since we purposely have reduced random as well as steeply dipping noise, the overall result is a more coherent (whiter) image. The antithetic fault ff' is slightly attenuated on the filtered section, due to removal of the steeply dipping fault-plane reflector. However, the major fault $\mathrm{FF}^{\prime}$ is now less ambiguous and can be traced on the time slice all the way south to line $\mathrm{AA}^{\prime}$, where at the $750-\mathrm{ms}$ level it has healed. The correlation between the faults on the vertical seismic section (Figure 7a) with low-coherency lineations present on the coherency time slices is now improved greatly. The wavelet-phase time

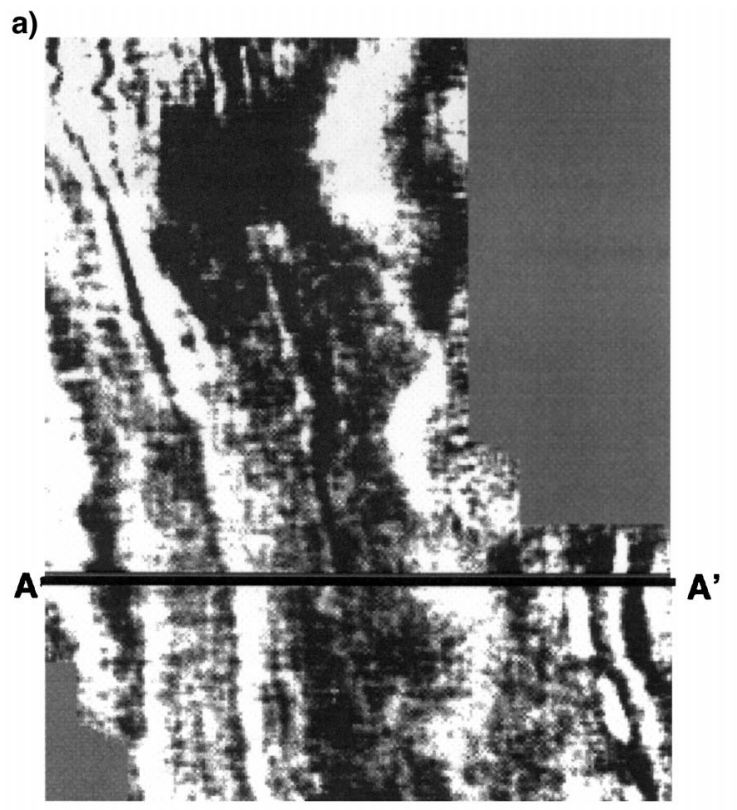

b)

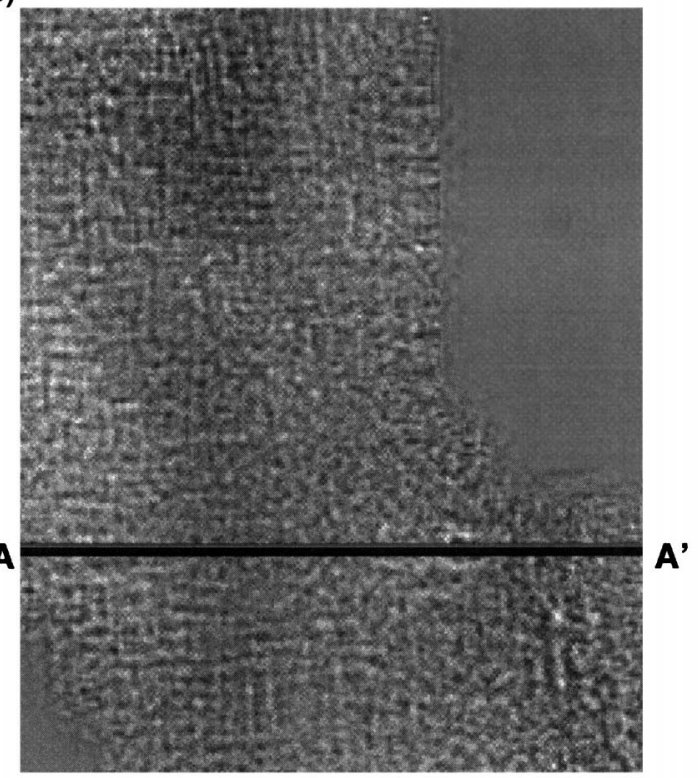

c)

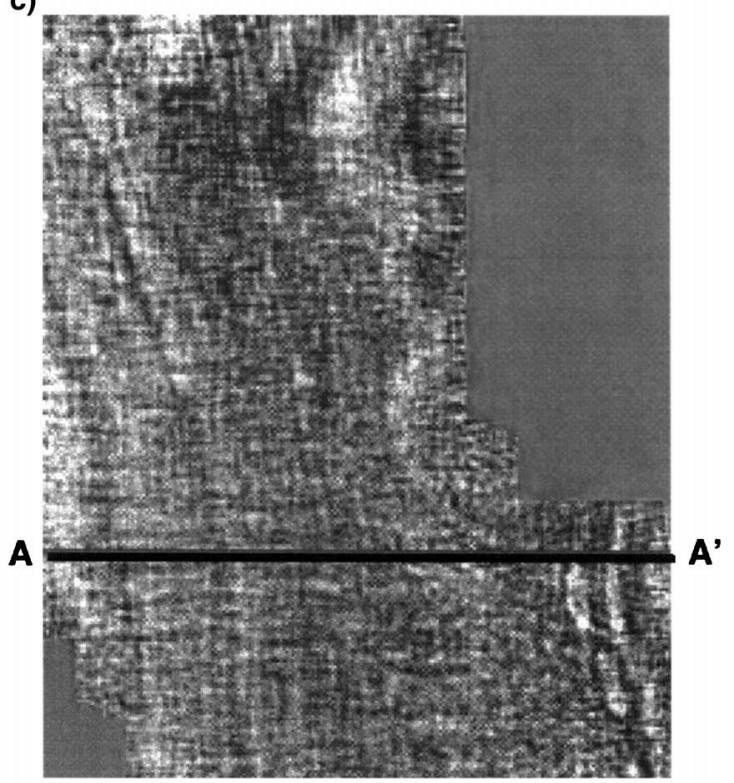

d)

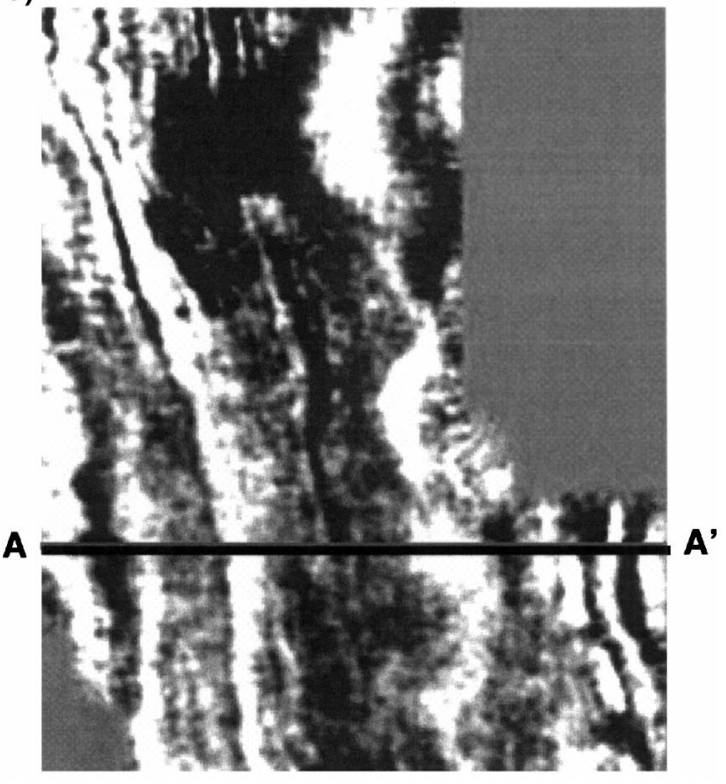

FIG. 13. Time slice at $832 \mathrm{~ms}$ through a 3-D time-migrated seismic data cube from the Permian basin, Texas: (a) raw data, (b) noise component with dips $0.2 \mathrm{~ms} / \mathrm{m}<s<0.4 \mathrm{~ms} / \mathrm{m}$, (c) rejected noise component with dips $s>0.2 \mathrm{~ms} / \mathrm{m}$, and (d) filtered data. 
slice generated on the filtered data (Figure 10a) is also much better correlated to the reflector wavelet phase one would interpret from the vertical section. We can improve the fidelity of the wavelet attribute estimates by exploiting our estimate of reflector dip and azimuth shown in Figure 11 and described by Marfurt et al. (1998). Simply stated, we calculate an average trace along the reflector from the 11 traces that fall within the analysis window. This reflector wavelet phase is displayed in Figure 10b. We exploit our coherency measurement

a)

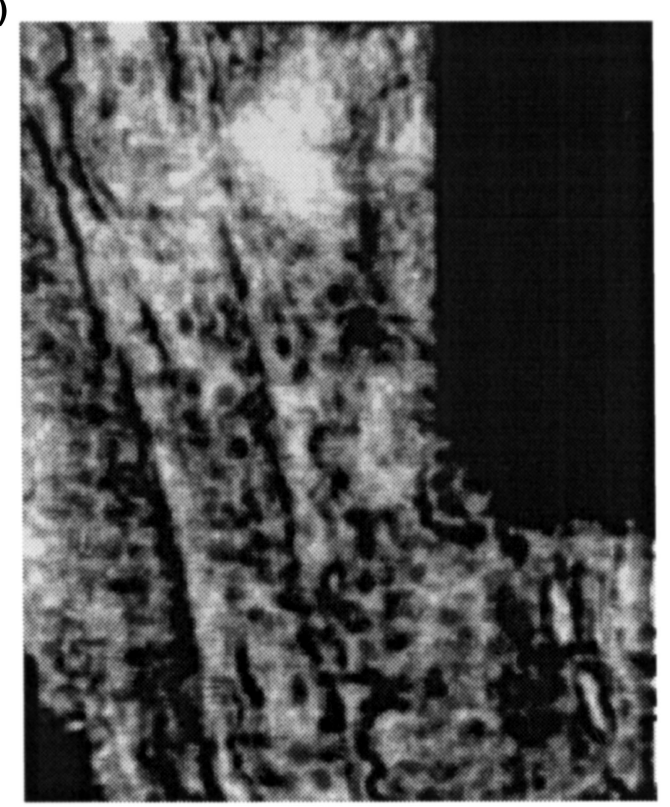

b)

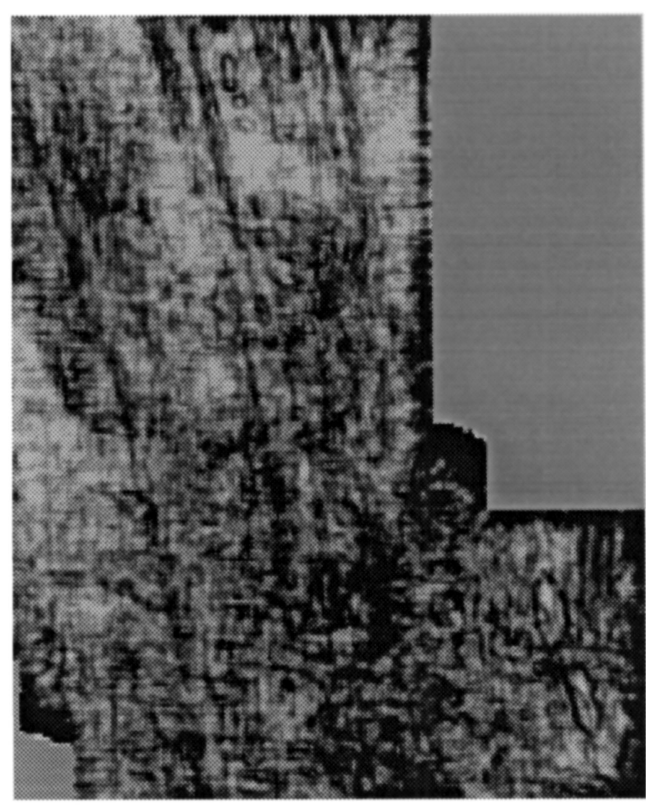

FIG. 14. Time slice at $832 \mathrm{~ms}$ through the coherency cube generating from the raw data using (a) the $\mathrm{C} 2$ algorithm and (b) the $\mathrm{C} 3$ algorithm. to estimate the probability that such a reflector exists. For this example, if the coherency $c<0.50$, we indicate the lack of a coherent reflector by the color black. Used together, coherency, dip/azimuth, and reflector wavelet phase of the filtered data are powerful tools in defining and correlating fault blocks.

\section{SUPPRESSION OF ACQUISITION FOOTPRINT ON LAND DATA}

Because of more flexible accessibility, 3-D land acquisition offers different data distributions than marine multistreamer

a)

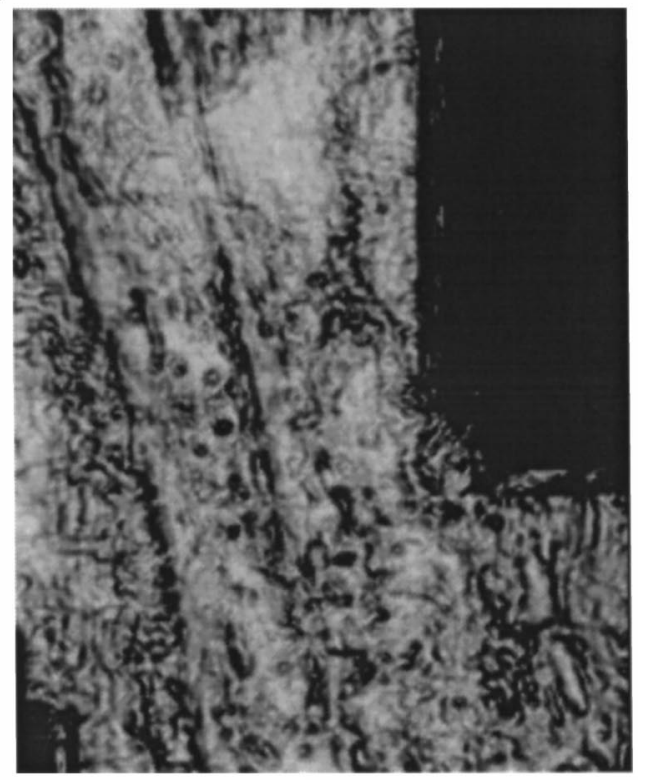

b)

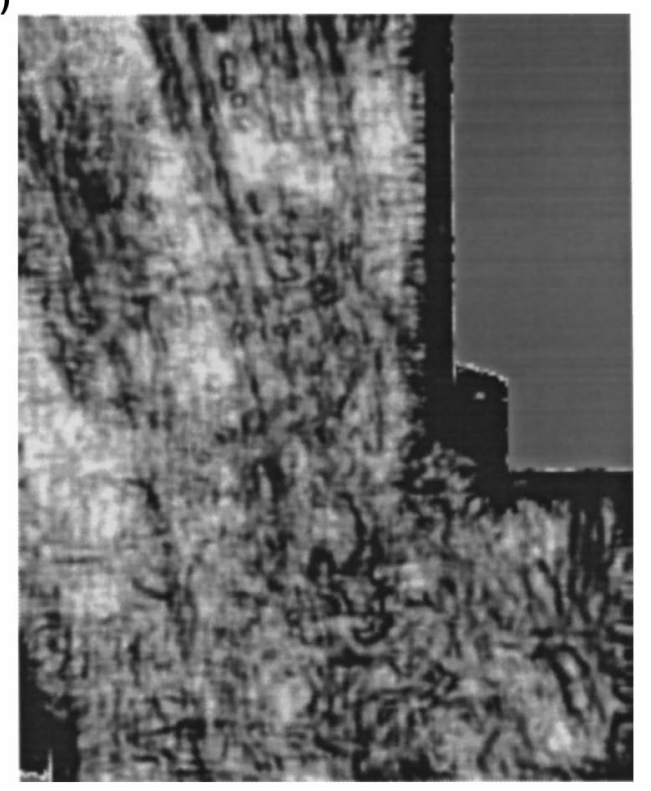

FIG. 15. Time slice at $832 \mathrm{~ms}$ through the coherency cube generated from the filtered data using (a) the $\mathrm{C} 2$ algorithm and (b) the C3 algorithm. 
acquisition. Those schemes with orthogonal source lines and receiver lines are particularly effective in providing a wide distribution of offsets and azimuths in any given bin (Stone, 1994). Typically, source and receiver arrays are only one dimensional, allowing for significant leakage of backscattered guided waves, including Rayleigh wave, Love waves, head waves, and their mode conversions.

Smith and McKinley (1996) have quantitatively analyzed four of the most popular 3-D acquisition techniques for leakage of coherent energy. While the larger distribution of azimuths is a great aid in reducing the ambiguity associated with velocity analysis in marine acquisition, the number of traces per bin remains low, such that any given row or column of bins may have a distinctly different distribution of azimuths and offsets from its neighbors. Combined with NMO stretch, this change in reflectivity with offset, or AVO effect, results in in-line and cross-line biases in signal amplitude that are superimposed on the in-line and cross-line leakage of aliased backscattered noise. All of these effects are exacerbated when we employ sparse 3-D acquisition techniques (Bouska, 1994) that allow for high-resolution 3-D surveys of large areal extent but with only six to seven traces per bin. It may appear that analysis of attributes may be difficult on such low-fold data; the poorer signal-to-noise ratio is often compensated by the higher resolution and larger areal extent that allow interpreters to place their attribute anomalies correctly within the larger depositional environment. Effective true-amplitude filtering of such data sets contaminated by aliased noise is still an area of active research.

Figure 12 shows a portion of a line from a 3-D survey acquired in the Permian basin of West Texas/eastern New Mexico. We note some clinoforms gently dipping toward the east, contaminated by aliased backscattered noise (Figure 12a). We employ a strategy analogous to our earlier marine data set and filter out dips ranging between $0.10 \mathrm{~ms} / \mathrm{m}<s<0.20 \mathrm{~ms} / \mathrm{m}$ to reject what clearly is aliased noise shown in Figure 12b. Unfortunately, this filter is not aggressive enough and we are forced to also reject dips, $s>0.20 \mathrm{~ms} / \mathrm{m}$, which correspond to amplitude changes in the signal attributed to NMO stretch and AVO variations from line to line. The rejected noise from such aggressive filtering is shown in Figure 12c, where we now see we have filtered out certain components of the signal. We show the results of such filtering on an input time slice at $832 \mathrm{~ms}$ (Figure 13). The cross-hatched pattern of rejected noise (Figure 13b) strongly correlates with the survey's north-south/east-west acquisition geometry. The seismic coherency using the $\mathrm{C} 2$ and $\mathrm{C} 3$ algorithm on the unfiltered data shows strong northnorthwest/south-southeast lineaments corresponding to the angular unconformities associated with the clinoforms (Figure $14 \mathrm{a}, \mathrm{b})$. The shorter east-west lineaments could be misinterpreted as small faults or fractures. It is also unclear whether the small pockmarks are real, are because of mismigrated shallower point scatters, or are attributable to interference of the east-west and north-south components of the acquisition footprint. The overall coherency on the filtered data shown in Figure $14 \mathrm{c}$ and $\mathrm{d}$ is increased; the east-west lineaments and many stray pockmarks are eliminated. Additionally, the angular unconformities are more continuous, and several strong pockmarks stand out prominently. Whether such pockmarks correlate with karsting or other diagenetic features or with variations in production or flow rates has yet to be tested by the drill bit.
As in our marine data case, the wavelet phase is also highly contaminated by the acquisition footprint (Figure 16a), with visible east-west and north-south striations running through the data. The reflector wavelet phase calculated along the instantaneous dip/azimuth of the filtered data (Figure 16b) shows a much cleaner result, with lineations and pockmarks that correspond neatly to the coherency time slice of Figure $16 \mathrm{~b}$. Clearly, geostatistical correlation of coherency and reflector

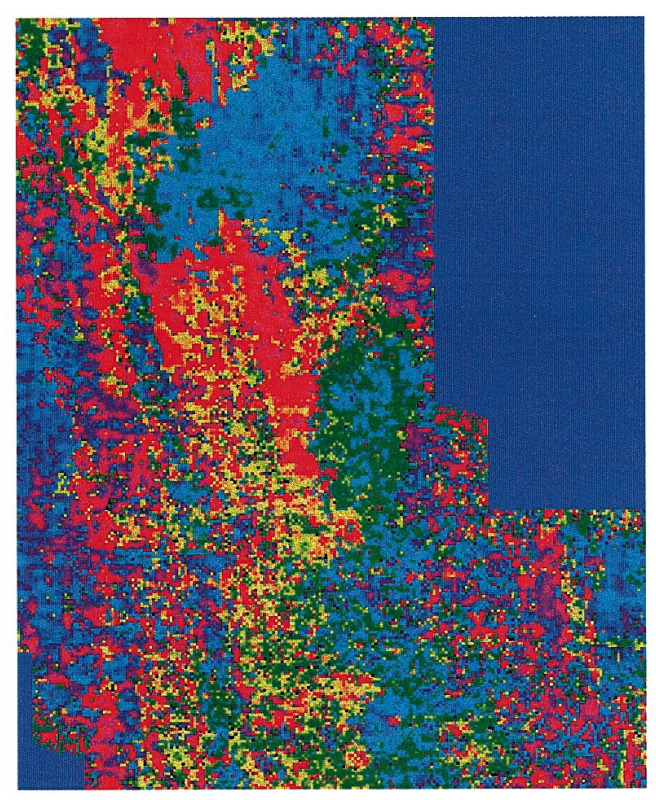

(a)

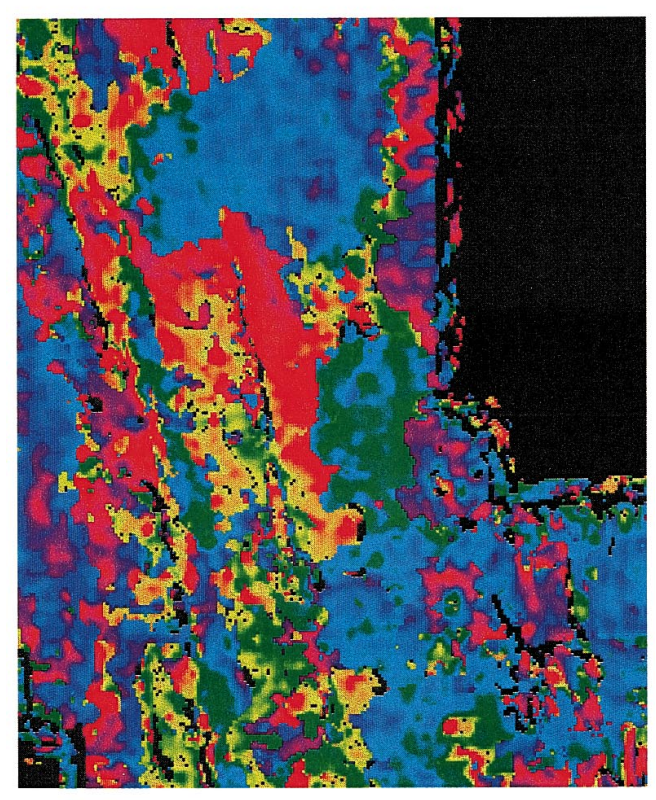

(b)

FIG. 16. Time slice at $832 \mathrm{~ms}$ through (a) wavelet phase cube generated from raw seismic data and (b) reflector wavelet phase cube generated along dip/azimuth surfaces predicted by the $\mathrm{C} 2$ algorithm on the $3-\mathrm{D}$ dip filtered data. 
wavelet phase with well production and flow rates would be higher for attributes generated on the filtered data than for those generated on the data contaminated by the acquisition footprint.

\section{CONCLUSIONS}

An acquisition footprint appears on almost all 3-D seismic data volumes to some degree. The causes of such footprints depend greatly on the details of the acquisition geometry and processing flow. Sometimes the acquisition footprint is correlated with seismic noise, as when backscattered surface waves leak into a linear array. Sometimes the acquisition footprint is correlated with signal, including strings of bins having a nonrandom distribution of offsets and azimuths, thereby sampling the expected variation of reflectivity with offset, or AVO effect, in an inconsistent manner. In a variation of this effect, acquisition may result in a pattern of lower fold bins, giving rise to distinct patterns of different signal-to-noise ratios. Finally, the acquisition footprint is often associated with processing artifacts, including NMO stretch, muting, dip moveout (DMO), and migration operator aliasing of inadequately sampled data.

Acquisition footprint negatively impacts powerful seismic analysis techniques such as seismic coherency and reflector wavelet attributes. The extent to which the footprint adversely impacts the analysis method depends on the specific characteristics of the root cause in the acquisition and processing. We are not yet very good at predicting the magnitude and characteristic of acquisition footprint on our 3-D data; however, it is quite easy to recognize the footprint when it is present.

Whether due to limitations in acquisition or processing, many of the effects of the acquisition footprint can be greatly diminished on seismic attributes by simple 3-D true-amplitude dip filtering of the input seismic data cube. Considerable care must be taken when dip filtering to preserve a sufficiently large component of the sharp edges necessary for the coherency algorithms. For this reason, we highly recommend dip filtering of unmigrated data, where the energy associated with sharp faults is usually in the form of smoother diffractions.

\section{ACKNOWLEDGMENTS}

We are grateful to Jim Smith of the Amoco EPTG Acquisition Team for his careful editing of this manuscript. The image processing $\left(k_{x}, k_{y}\right)$ approach to footprint suppression shown in Figure 5 is from Paul Gutowski and Paul Garossino. We thank Jim Ward of our Permian basin BU for supplying our land data set and for the fruitful symposia he conducted in Amoco's West Lake 4 offices. We are also indebted to Teresa Stenslie and Vicki Wilson of ATTC Document Services for their great care and patience in putting this document together.

\section{REFERENCES}

Bahorich, M. S., and Farmer, S. L., 1995, 3-D seismic coherency for faults and stratigraphic features: The Leading Edge, 14, 1053-1058. 1996, Methods of seismic signal processing and exploration: U. S. Patent 5563949.

Bodine, J. H., 1984, Waveform analysis with seismic attributes: 54th Ann. Internat. Mtg., Soc. Expl. Geophys., Expanded Abstracts, 84.

Bouska, J., 1994, Between a rock and a hard place: Using heliportable 3 -D seismic to address the problems of carbonate outcrop in the Canadian Rocky Mountain Thrust Belt: 64th Ann. Internat. Mtg., Soc. Expl. Geophys., Expanded Abstracts, 1641-1643.

Gersztenkorn, A., and Marfurt, K. J., 1996, Coherency computations with eigenstructure: 58th Ann. Internat. Mtg., Eur. Assn. Expl. Geophys., Expanded Abstracts, x031.

Marfurt, K. J., Kirlin, R. L., Farmer, S. L., and Bahorich, M. S., 1998, 3-D seismic attributes using a running window semblance algorithm: Geophysics, in press.

Marfurt, K. G., Schneider, R. V., and Mueller, M. C., 1996, Pitfalls using conventional and discrete Radon transforms on poorly sampled data: Geophysics, 61, 1467-1482.

Regone, C. J., and Rethford, G. L., 1990, Identifying, quantifying, and suppressing backscattered seismic noise: 60th Ann. Internat, Mtg., Soc. Expl. Geophys., Expanded Abstracts, 748-751.

Smith, J., and McKinley, J., 1996, Reduction of the acquisition footprint due to direct arrival linear noise in 3-D seismic acquisition design, especially "Whatever happened to 3-D groundroll?": 65th Ann. Internat. Mtg., Soc. Expl. Geophys., Expanded Abstracts, $72-75$.

Stone, D. G., 1994, Designing surveys in two and three dimensions, in Meeder, C. A., Ed., Geophysical reference Series 5: Soc. Expl. Geophys.

Taner, M. T., Koehler, F., and Sheriff, R. E., 1979, Complex seismic trace analysis: Geophysics, 44, 1041-1063.

Vermeer, G. J. O., 1990, Seismic wavefield sampling: A wavenumber approach to acquisition fundamentals, in Cooper, M. R., Ed., Geophysical references 4: Soc. Expl. Geophys. 